\title{
A Classroom Exercise to Teach Undergraduates to Critically Think Using Primary Scientific Literature
}

\author{
Anne Marie Zimeri
}

Department of Environmental Health Science, University of Georgia, Athens, GA

*Corresponding author: Anne Marie Zimeri, Phd, Assistant Professor, Department of Environmental Health Science, University of Georgia, 150 Green Street Athens, GA 30606; E-mail: zimeri@uga.edu

\begin{abstract}
Critically thinking about scientific data to form opinions on controversial issues in environmental health is crucial in undergraduate education in environmental health. An assignment paired with a classroom activity was designed to impart knowledge on how to search the primary literature and extract data that can help formulate a point of view on several environmental health topics including endangered species designation, genetic engineering, organic farming, population control, worldwide banning of DDT, mining/drilling, sushi, nationalized health care. Data are presented that show the assignment was effective in motivating critical thinking and making students take sides on these issues based on data that may impact their lives and political choices in the future.
\end{abstract}

Keywords: Primary literature; Critical thinking; Environmental assignment; Flipped classroom; Environmental health; Fact sheet; Environmental behavior
Received date: May 10, 2016

Accepted date: August 23, 2016

Published date: August 31, 2016

Citation: Zimeri, A.M. A Classroom Exercise to Teach Undergraduates to Critically Think Using Primary Scientific Literature. (2016) J Environ Health Sci 2(1): 1- 4 .

DOI: $10.15436 / 2378-6841.16 .914$

\section{Introduction}

Environmental health education (EE) requires training in critical thinking skills because many issues have several points of view. Students need to be trained to look at data and decide where they lie on the spectrum of opinions when it comes to environmental issues. This is especially important because the media, in an attempt to portray both sides of an issue, may give equal weight to each side of the story when there may be overwhelming evidence on one side and a few dissenting papers in the literature on the other. Teaching students to go to the literature to see the data for themselves is an important skill so that they can make decisions about a topic based on data and not conjecture or value statements. This has been shown to be a challenge because scientific information does not always overcome the barriers of decision making (Arvai, Campbell, Baird, $\&$ Rivers, 2004). Additionally, students require practice in using critical thinking to make data based decisions (Holmes, Wieman, $\&$ Bonn, 2015). However, students who are exposed to environmental issues tend to be more influenced by those issues when it comes to political decision making, which makes it all the more important that they employ critical thinking skills when forming opinions about environmental issues (Goldman, Ayalon, Baum, \& Haham, 2015).

Instructors have many tools to stimulate critical thinking about the environment. Project-based learning is one approach that has been shown to stimulate critical thinking and have a positive effect on students' environmental attitudes (Benzer \& şAhIN, 2013; Genc, 2015). And, active learning techniques that have been used with undergraduates have better prepared them to cope with the thinking required for graduate level courses (Duncan, Tasich, Burkhardt, Benneyworth, \& Duncan, 2015; Jensen, Kummer, \& Godoy, 2015). Students generally trust instruction-based science and technology (Liu \& Lin, 2014), but extra steps may be necessary in order for them to use their knowledge to inform and direct their decisions regarding the environment. There has been work to show that some environmental programs for students can give them the intent to make decisions based on the science (Hadjichambis, Paraskeva-Hadjichambi, Ioannou, Georgiou, \& Manoli, 2015), 
but self-identity (McGuire, 2015), family attitudes (Guuastello), a students' major (Lang, Ozdmir, Schmidt-Harsh), and trying an activity for a brief period of time that promotes stewardship (Zimeri, 2015) may play a role in environmental decisions. Most effective for student environmental based decisions for is a variety of entry level factors, like acquiring the knowledge, followed by an ownership variable, and various empowerment variables (Hungerford \& Volk, 1990).

Fact sheets are used commonly in environmental health to communicate information to target audiences. The Agency for Toxic Disease Registry (ATSDR) uses fact sheets to communicate with the public (http://www.atsdr.cdc.gov/toxfaqs/index. asp) and health educators have used fact sheets to communicate health information to students and the public (Weiler, 1998). Here a fact sheet assignment is presented that gives students ownership over which topic they will investigate, cultivates timely knowledge with a classroom activity, and makes students conversant on controversial environmental topics in which they can use facts from the scientific literature rather than value judgments to formulate an opinion that may lead to better informed environmental decisions.

\section{Materials and Methods}

\section{Participants}

Surveys were distributed by a teaching assistant to 2 Introductory to Environmental Health Science classes; one with 77 students, the other with 56 students. The surveys were in paper format with 12 questions on the front and 3 questions on the back of the page. Out of the 133 students to whom the survey was distributed, 109 participated. Of those 109, 104 answered all of the questions. Five students did not answer the three questions on the back of the paper. Results for all questions were not significantly different between the two classes so the data were combined and are presented in summary form. The survey was distributed two weeks after the assignment was due and the related classroom activates were completed. The surveys and the study were approved by the University of Georgia Institutional Review Board.

\section{The assignment instructions}

Twenty minutes of class time was taken to walk students through using NCBI Pubmed to find peer-reviewed articles using specific keywords that they developed based on a short introduction to each of the potential topics for the assignment (endangered species designation, genetic engineering, organic farming, population control, worldwide banning of DDT, mining/drilling, sushi, nationalized health care). Students were also shown review articles, and the difference between review articles versus a primary article was discussed.

Assignment posting on class website: The following was posted on the Desire to Learn supported class website under the assignment dropbox:

Objective: In a one page fact sheet, develop or argue a main point or (non-trivial) thesis in an interesting way dealing with one of the following environmental topics:

Endangered species designation, genetic engineering, organic farming, population control, worldwide banning of DDT, mining/drilling, sushi, nationalized health care.
I am looking for a genuine effort to reflect on these issues and discover and express an opinion or interpretation in an organized, referenced, and coherent manner.

Your fact sheet should include:

1) an introductory paragraph of the subject

2) your opinion on the subject

3) scientific data* that strengthens your opinion (from a peer reviewed journal from NCBI). Refer specifically to the figure or table number with the supportive data in the paper you choose.

*Reference and discuss the DATA from at least one paper published a peer reviewed journal found on the NCBI Pubmed database. Journal articles must be from 2008 to 2016. Do NOT use review articles.

4) the opposing view

5) who, in government, supports your point of view?

6) your prediction for the future of your subject

Fact sheets must be submitted to the drop box along with a PDF copy of the journal article that includes your main piece of data.

\section{Classroom activity instructions}

After the student fact sheets were graded and feedback was posted to the class assignment drop box, one class period was allowed for students to get into groups by topic and compile their facts for a presentation. The students were instructed to make no more than five Power point slides so that their presentations could be easily limited to 8 minutes. Other information to be included in the presentation was background information on the controversy and their points of view on the topics as well as who, in government, supported each point of view. Students were also asked to compose three multiple choice questions and two short answer questions to post on the discussion board of the class website. One question from each set was to be on the exam if composed well. The next class period, students presented their topics.

\section{Results}

The 3000-level Introduction to Environmental Health class in which this assignment and activities were performed was mostly female. Of the 109 participants, 85 (78\%) were female and $24(22 \%)$ were male. Most were upper level students in their junior or senior year in school (table 1A). Because advanced placement scores can allow for younger students to be classified as upper level students, ages were taken as well (table 1B) [Tables 1A and 1B near here]. Although it is possible for freshman to be 17 years of age, the letter of consent specifically required that only students 18 or above participate (all survey questions had Internal Review Board Approval).

Table 1A: Number of participants in each year of school of the 109 survey participants.

\begin{tabular}{|l|c|}
\hline Year in school & Number of participants \\
\hline Freshmen & 8 \\
\hline Sophomores & 11 \\
\hline Juniors & 46 \\
\hline Seniors & 38 \\
\hline $5^{\text {th }}$ year seniors & 5 \\
\hline $\mathbf{6}^{\text {th }}$ year seniors & 1 \\
\hline
\end{tabular}


Table 1B: Age of participants from the 109 surveys returned.

\begin{tabular}{|c|c|}
\hline Age of participant & Number of participants \\
\hline 18 & 6 \\
\hline 19 & 11 \\
\hline 20 & 29 \\
\hline 21 & 35 \\
\hline More than 21 & 28 \\
\hline
\end{tabular}

All of the topics were selected by at least 7 students, but there were two clear front runners for topics: DDT and genetically modified organisms. These two topics were selected by $25 \%$ and $19 \%$ respectively. The remaining topic selection is shown in table 2 [Table 2 near here].

Table 2: Topics distribution of the 109 survey participants.

\begin{tabular}{|l|c|}
\hline Topic & Number of participants \\
\hline Sushi & 13 \\
\hline Nationalized Health Care & 7 \\
\hline DDT & 27 \\
\hline Endangered Species & 15 \\
\hline Genetically Modified Organisms & 21 \\
\hline Mining/drilling/fracking & 9 \\
\hline Population Control & 10 \\
\hline Organic Farming & 7 \\
\hline
\end{tabular}

On the survey, students were given several selections for reasons why they chose their topics. The selections were developed from anecdotal conversations the instructor has had with students for the few semesters that the assignment has been implemented. Fifty students selected "I was already familiar with the topic". Both "I wanted to select a topic about which I knew very little" and "I randomly chose a topic" were selected by 19 students each. Five students chose "I chose a topic based on my classmate/friend's selection". The remaining 16 students chose other.

Students were also asked how long the assignment took to complete to see whether the point value allotted to the assignment was reasonable. Sixty-six percent completed the assignment in $1-3$ hours, 29\% completed it in $4-6$ hours, and 5\% needed more than six hours to complete the assignment.

Based on the description given in class in which a demonstration of a literature search on NCBI Pubmed was performed, and the assignment description posted on the class website, students were asked whether the learning objectives were clear. One hundred of the students chose "yes" when asked if the objectives were clear, while only 9 chose "no". Students were also asked whether they formed an understanding of how to search the peer-reviewed scientific literature and 103 chose "yes" while only 6 chose "no". During the classroom demonstration of searching the literature, a review article was shown and discussed so that students could distinguish between review articles and primary papers, which is what they were required to use for the assignment. Students were asked "Can you distinguish between a primary article and a review article?" The majority, 101 students, chose "yes", and the remaining 8 students chose "no".

To assess the flipped classroom learning activity students were asked, "Did compiling your data with other members of your group deepen your understanding of your topic?" There were 104 responses to this question. Eighty-two students chose "yes", and 22 students chose "no". To further delve into the classroom activity to determine whether sharing group topics in presentation form was informative, students were asked "Did the other student group presentations give you a clear understanding of the controversy associated with their topics?" The majority of the students, 92, selected "yes", and 12 selected "no".

Because one of the learning objectives was for students to be conversant about these topics armed with scientific facts, they were asked which of three choices described their understanding of their topics after compiling their data and giving their presentation. No students chose "I do not understand the topic". Sixty of the 104 responses selected "I am conversant on the topic" and the remaining 44 selected "I could defend my point of view using the scientific facts I learned on the topic". Students were also asked similar question to assess their understanding of the topics presented other than their own. The majority of students, 94, selected "I have enough information to be conversant of the topics", the remaining 10 response were divided between "I have a deep understanding surrounding the controversy related to the topics" ( 6 students) and "the presentations did not add to my knowledge base regarding the topics" (4 students).

The final survey question was a free response and asked "Do you have any suggestions that would make this assignment better able to accomplish the learning objectives?" Few students answered, but of those who did their responses were as follows: No-Ifeel they were easily accomplished, Smaller groups, It was great! More group work time, Give more presentation guidelines, Give more background info. On the topics choices in class Offer more topic options, let students make suggestions, Clearer instructions, Loved the format and learned a lot from other students, The hardest part was finding an article, forcing students to be on either side of the debate and then debating in class would be good, Provide more topics, More topics to choose from, Narrow the topics, Clearer presentation expectations, Smaller groups, Make the presentation guidelines better, I liked the broadness and freedom of it, It's hard to manage such big groups, You could supplement the student info., Shorter, to the point presentations, I already knew how to do research using peer-reviewed sources, Have groups make a group fact sheet on both opinions, Ask students to pick a topic they know the least about, Allow other topics, It was difficult to find an article, Clearer guidelines on assignment formatting, I had a hard time keeping it to one page, I actually really enjoyed doing the fact sheet, Topics were too broad to compile into one presentation

\section{Discussion}

Including critical thinking exercises to teach students how to evaluate scientific topics is crucial in environmental health education and undergraduate education, in general. This new generation of students will be tasked with finding solutions to environmental problems that can be controversial and include many value judgments that are passed on to the public and can lead to continued environmental degradation if not accurate. For example, a portion of the public and politicians still do not accept that global climate change is real despite an overwhelming body of evidence in the scientific literature that states otherwise. Students must be able to assess topics from a critical thinking 
standpoint to help shape their world and especially to mold their political and everyday activities.

This fact sheet assignment data show that students can learn about a topic in a fact-based way with the assignment design presented here. The majority of students feel conversant and knowledgeable about the topics based on the facts they shared within their groups and from their peers in other groups.

Though the survey was administered at the end of the semester by a teaching assistant who explained that surveys would not be reviewed until grades were posted, it is possible that students skewed some of their answers to please the instructor or if disgruntled, to give a false poor review. This limitation was addressed by survey anonymity and again, by the promise that surveys would not be reviewed until final grades was posted.

\section{Conclusions}

The fact sheet assignment and accompanying classroom activity presented here was shown to increase the knowledge base of students with regard to several timely environmental health science topics. Each topic had a controversy associated with it such that students could investigate the points of view from both sides and select which side they agreed with based on a scientific fact that they mined from the current peer-reviewed scientific literature. The assignment was designed to teach students about the peer review and publication process, how to search the literature, and how to critically think about an article from the literature such that they could formulate an opinion about a topic based on that fact.

Students were surveyed about their experience and the majority of students selected a topic with which they had some familiarity. Still, the students felt that they had a deeper knowledge of all the topics, including their own, after the flipped classroom exercise. This assignment and associated flipped classroom activity may add to the suite of critical thinking skills of students in not only environmental health sciences, but also in other fields in which there are disputes or myths that can be debunked using the scientific literature.

\section{Conflicts of Interest: None}

\section{Reference}

1. Arvai, J.L., Campbell, V.E.A., Baird, A., et al. Teaching Students to Make Better Decisions About the Environment: Lessons From the Decision Sciences. (2004) J Environ Edu 36(1): 33-44.

2. Holmes, N.G., Wieman, C.E., Bonn, D.A. Teaching critical thinking. (2015) Proc Natl Acad Sci U.S.A. 112(36): 11199-11204.

3. Goldman, D., Ayalon, O., Baum, D., etal. Major Matters: Relationship between Academic Major and University Students Environmental Literacy and Citizenship as Reflected in Their Voting Decisions and Environmental Activism. (2015) Int J Environ Sci Edu 10(5): 671-693. 4. Benzer, E., şAhIN, F. The Effect of Project Based Learning Approach on Undergraduate Students' (2013) Environmental Problem Solving Skills 12(2): 383-400.

5. Genc, M. The Project-Based Learning Approach in Environmental Education. (2015) International Research in Geographical and Environmental Education 24(2): 105-117.

6. Duncan, B.R., Tasich, C.M., Burkhardt, B.L., et al. Getting the Most Out of Dual-Listed Courses: Involving Undergraduate Students in Discussion Through Active Learning Techniques. (2015) J Coll Sci Teaching 45(1): 24-31.

7. Jensen, J.L., Kummer, T.A., Godoy, P.D.D.M. Improvements from a Flipped Classroom May Simply Be the Fruits of Active Learning. (2015) CBE - Life Sci Educ 14(1): 1-12.

8. Liu, S.C., Lin, H.S. Undergraduate Students' Science-Related Ideas as Embedded in Their Environmental Worldviews. (2014) Int J Sci Math Edu 12(5): 1001-1021.

9. Hadjichambis, A.C., Paraskeva-Hadjichambi, D., Ioannou, H., et al. Integrating Sustainable Consumption into Environmental Education: A Case Study on Environmental Representations, Decision Making and Intention to Act. (2015) Int J Environ Sci Edu 10(1): 67-86.

10. McGuire, N.M. Environmental Education and Behavioral Change: An Identity-Based Environmental Education Model. (2015) Int J Environ Sci Edu 10(5): 695-715.

11. Zimeri, A. Environmental Pledge Assignment: Connecting classroom lessons to behavioral changes with calculable impacts. (2015) Polymath 5(3): 1-11

12. Hungerford, H.R., Volk, T.L. Changing learner behavior through environmental education. (1990) J Environ Edu 21(3): 8-21.

13. Weiler, R.M. Developing Fact Sheets. (1998) J Health Edu 29(1): 46-50.

\author{
Ommega Online Publishers \\ Journal Title: Journal of Environment and Health Science (JEHS) \\ Journal Short Name: J Environ Health Sci \\ Journal ISSN: 2378-6841 \\ E-mail: environmentalscience@ommegaonline.org \\ Website: www.ommegaonline.org
}

